\title{
Foundations for improved integration - Using Systems Engineering in Programme and Project Management
}

\author{
Andrew Gray \\ BMT Hi-Q Sigma Ltd. \\ Bath, UK \\ +44 1225820980 \\ Andrew.Gray@BMT-HQS.com \\ Helen Nasser \\ WSP Parsons Brinkerhoff \\ London, UK \\ Helen.Nasser@pbworld.com
}

\author{
Dr. Adrian James \\ UCL Australia \\ Adelaide, Australia \\ +61881109976 \\ A.James@ucl.ac.uk \\ Ken Richardson \\ Roke Manor Research Ltd. \\ Romsey, Hampshire, UK \\ Ken.Richardson@roke.co.uk
}

\author{
Kate Rooke \\ PA Consulting Group \\ London, UK \\ Kate.Rooke@paconsulting.com
}

Copyright $\odot 2017$ by A.Gray, Dr.A.James, H.Nasser, K.Richardson \& K.Rooke. Published and used by INCOSE with permission.

\begin{abstract}
The INCOSE UK/APM Joint Working Group (JWG) on Systems Engineering (SE) and Project/Programme Management (PM) Integration has been addressing the shared understanding of the two disciplines and how they work together. It seeks to promote the benefits of systems thinking across the wider decision-making community, and to understand how to deliver these benefits.
\end{abstract}

As part of its work, the JWG has compared and categorized life cycles and processes within the two disciplines; analysed subsequent theoretical touch points, overlaps and fusion areas; identified examples of actual large projects with integrated SE and PM approaches; and used all this information to generate a set of underlying Principles for improved integration. In addition, the JWG has identified a set of Top Tips to help establish the Principles.

This information forms part of the expanding body of knowledge being developed by the JWG and helping to lay the foundation for improved integration.

\section{Introduction}

Learning from past experience to support future success. This paper describes some of the findings of a working group established to consider how best to increase the level of mutual understanding between Systems Engineering (SE) and Programme and Project Management ${ }^{1}$ (PM) practitioners, and obtain greater value through the application of SE principles and techniques to PM activities (and vice-versa).

There is increasing recognition that the Systems Engineering and Project Management communities need to work at greater levels of integration in order to undertake complicated large-scale (and often

\footnotetext{
${ }^{1}$ Within the context of this paper the terms 'project' and 'project management' (and abbreviation PM) also represent programmes and portfolios and their associated management disciplines unless indicated otherwise.
} 
complex) projects. This recognition can frequently be anecdotal and based on the experience of individuals, as well as developments in theories, processes and standards. It is therefore important to also identify a body of evidence of the potential benefits (and pitfalls) of increased integration in order to support, highlight and disseminate good working practices across both communities. By using such evidence in conjunction with developments in processes and working practices it should then be possible to distil the guidance and advice into a set of principles and guidance for practitioners.

The Joint Working Group. The INCOSE UK \& Association for Project Management (APM) Joint Working Group (JWG) on Systems Engineering and Project Management (SEPM) was formed in July 2013 as a result of a recognition by both organisations that closer integration of the two disciplines should increase the probability of project success. Its aim is ...

\section{To develop and promote good practice and guidance dovetailing SE and PM and promote systems thinking across the wider decision-making community in the UK (and to influence developments internationally) in order to support the improved delivery of complex projects and avoid common pitfalls.}

During its first phase, the JWG was composed of eight work streams (WS), shown in Table 1, which were established in order to (i) define the benefits and value of increased SE and PM integration, (ii) provide a focus in how to deliver these benefits, (iii) communicate the benefits to a wide range of audiences.

Table 1. SEPM JWG Work Streams

\begin{tabular}{|c|c|}
\hline \multicolumn{2}{|c|}{ What are the benefits? } \\
\hline WS 1 & Compelling value proposition \\
\hline How to deliver the benefits? \\
\hline WS 8 & Life cycles and processes \\
\hline WS 4 & Roles and responsibilities \\
\hline WS 6 & Competency framework \\
\hline WS 7 & Education and training \\
\hline How to promote the benefits? \\
\hline WS 2 & Communication \& exploitation \\
\hline WS 3 & Guidance material \\
\hline WS 5 & Case studies \\
\hline
\end{tabular}

The JWG is yet to publish in full the initial Body of Knowledge generated from this first phase of work, but some of the outputs have already been disseminated. In particular, an INCOSE UK Zguide (Z11) was presented at the INCOSE UK Annual Systems Engineering Conference (ASEC) 2013 (Cowper \& McGlynn 2013), a one-page value proposition and a poster describing outputs were provided at ASEC 2014 (SEPM JWG 2014), and a presentation based on the work of the JWG was made at the APM Conference in 2015 (Cooke \& Rooke 2015). A paper drawing on the work on lifecycles and processes was presented at ASEC 2015 (Gray \& Richardson 2015), and the work described in this paper continues that narrative.

Integrating the Work Streams. This paper examines ways of exploiting the value of greater SE and PM integration through the SEPM JWG work, principally looking at Life Cycles and Processes 
("WS 8" in Table 1), Case Studies ("WS 5") and Guidance Material ("WS 3"). WS 8 has identified where SE and PM models, approaches and ways of working overlap; it has explored and categorized the range of life cycle representations, and based on the findings, it has developed a unified conceptual model to help illustrate the touch points between the disciplines. WS 5 has worked to identify examples of integrated activities from large-scale complex programmes in the UK. WS 3 has subsequently developed guidance material for SE practitioners based on the outputs and findings across the JWG. It is important to note that this work has not been undertaken in isolation but in conjunction with the efforts of the JWG across all work streams to arrive at a coherent body of knowledge and guidance material.

\section{The Joint Working Group approach Identifying the range of life cycle and process definitions}

Continuing ASEC narratives. The work of the JWG on life cycles and processes is a continuation of existing narratives within the SE and PM communities, of which the UK Annual Systems Engineering Conference (ASEC) - and its predecessors - forms an important part. These narratives have informed an important element of the research approach taken by the JWG in comparing, contrasting and consolidating information gathered from many sources, and interpreting this information in ways that could provide benefit to both SE and PM practitioners.

Firstly, at the 2009 UK Autumn Assembly, Rick Adcock \& Andrew Farncombe re-examined various SE life cycle models and approaches (Adcock \& Farncombe 2009), looking to review their applicability and identify areas for future work. This theme was subsequently picked up and discussed by a Bristol Local Group workshop (Brain \& Gibson 2011).

Secondly, at ASEC 2011, Mark Fielding-Smith presented the results of a SELEX/UCL survey into the behaviours of PM and SE practitioners and the integration of programme management and SE approaches (Fielding-Smith 2011), which included recommendations to review and consider the integration between SE and PM processes.

Both of these narratives have been used as a springboard by the JWG to bring elements together from a variety of other sources, and an interim set of findings was provided at ASEC 2014 (SEPM JWG 2014), followed by a paper describing the value of PM/SE integration at ASEC 2015 (Gray \& Richardson 2015).

Life cycle representations. Key sources of information for identifying the wide range of life cycle representations included the INCOSE SE Handbook, the APM Body of Knowledge, the PMI Body of Knowledge (PMBOK®) and various sector-specific examples from the fields of defence, construction, aerospace, software generation, transportation and health care. Information was also drawn from the Axelos Best Management Practice suite (including MoP®, MSP®, PRINCE2®).

Process comparisons. Information on SE and PM processes was drawn from the same key sources as for life cycles. In addition, the ISO standards for SE (ISO15288:2015) and Project Management (ISO21500:2012) allowed a direct comparison of processes on a consistent basis, as shown in Figure 1. 


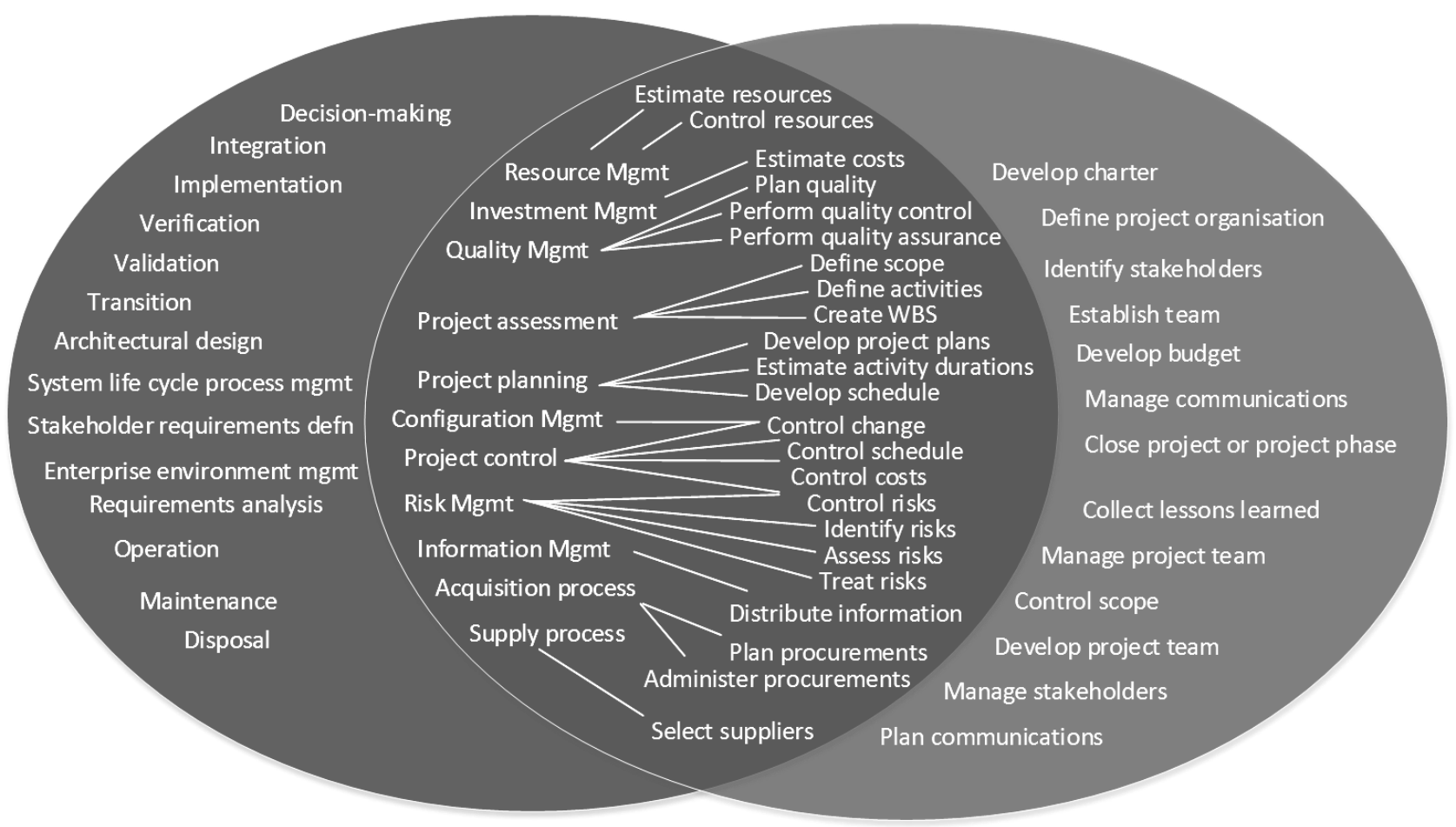

Figure 1: Example comparison of processes for SE and PM (using ISO definitions)

\section{Identifying and building case studies}

Identifying examples of integration. The aim of Work Stream 5 was to gather, analyse and review project examples and other research documentation in the use of good practice of Systems Engineering and Project Management. Projects were identified through public domain literature searches and APM and INCOSE UK material. In some cases this literature was supplemented through interviews held with key personnel and technical experts (particularly where publically available information was limited). Individual reports were then written for each case study, laying out the background and activities of each project and identifying practices that supported achievement of the project objectives. All of the information in this paper has been gathered from the executive summaries produced for each of the case studies (Nasser 2016). The case studies selected for inclusion in this paper have been taken from the transportation infrastructure sector:

1. Thameslink ${ }^{2}$ Programme transforming north-south rail connections across London

2. East London Line Project ${ }^{3}$ to deliver a new Overground route connecting East London to South London

3. Establishing the second of two new centralised UK National Air Traffic Service (NATS) Air Traffic Control Centres at Prestwick, Scotland ${ }^{4}$

4. The construction of Heathrow Airport Terminal 5 (T5) ${ }^{5}$

\footnotetext{
${ }^{2}$ For further details see http://www.thameslinkprogramme.co.uk/about-us

${ }^{3}$ For further details see https://tfl.gov.uk/modes/london-overground/

${ }^{4}$ For further details see http://www.nats.aero/about-us/what-we-do/our-control-centres/

${ }^{5}$ For further details see http://www.britishairways.com/en-gb/information/airport-information/london-heathrow-airport/heathrow-t5
} 


\section{Identifying the principles for enabling integration}

The need for simplicity. From the beginning it was identified that the outputs from the JWG needed to meet the following key criteria:

1. The outputs need to be based on evidence collected through case studies, comparative analysis and interviews;

2. The outputs need to be tested through focused workshops and conferences;

3. The outputs need to be easily communicated with a wide stakeholder group.

In order to communicate the information easily it was decided to establish and refine a set of principles and top tips which could be included in presentations and other material. Initially, these tips were created through focused sessions with the JWG, which has representation across industry sectors and both the systems engineering and project management communities. They were then refined and verified through a series of steps:

1. As the interviews and case studies were completed the principles were validated and updated based on the qualitative evidence from reports and individual interviews. This also included the identification of key barriers.

2. A verification workshop was held at the ASEC 2015 conference (Rooke 2015) which looked at the barriers to integration and the management of the interfaces across a generic lifecycle.

3. A further research session was conducted at a UK government agency with over 80 systems engineers and project managers. This provided quantitative feedback on the agency's organisational performance against the principles as well as qualitative feedback on the principles.

4. A final working group session consolidated the information that had been gathered into a final set of principles, barriers and tips.

\section{Results of analysing the range of representations}

SE vs PM terminology. It is important for mutual understanding that common terminology is used, or at least the differences in terminology are recognised and understood. For example, there is a key difference in the principal use of the term 'life cycle' by the two communities. A project or programme life cycle is typically focused on the creation of a system (or product) rather than the life cycle of the system (or product) itself, as shown in Figure 2. Other terms such as 'Stage' or 'Phase' are used interchangeably in some cases, but have specific meanings in other situations (for example the term 'Stage' within the PRINCE2® framework).

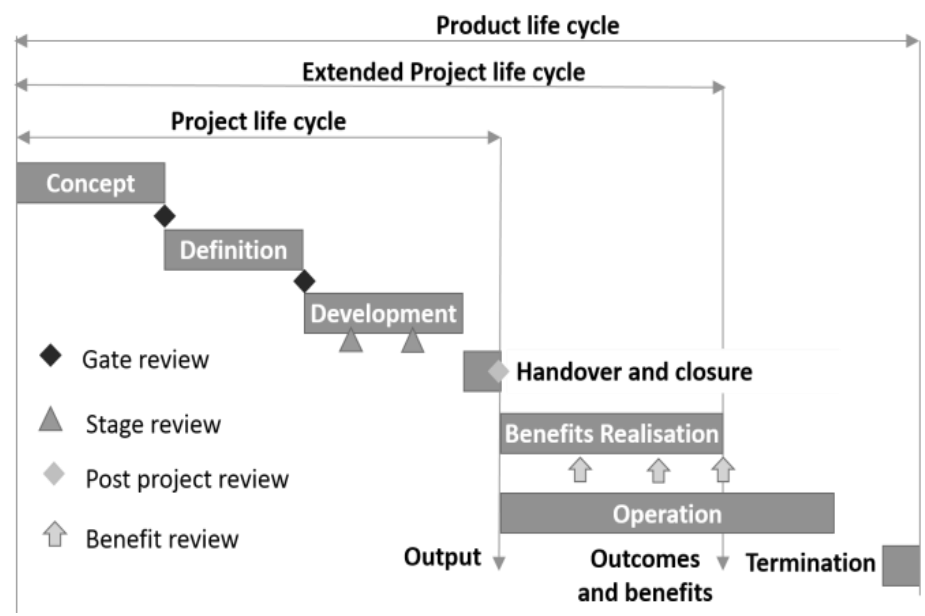

Figure 2: Comparison of project vs product life cycle (APMBoK 2016) 
Addressing a multitude of life cycle representations. There are many different representations by which life cycles are understood, deployed or navigated, and these can be influenced by objectives, environments, organisations and other incentives or constraints. In order to aid the aggregation and communication of information across SE and PM practitioners, a common terminology has been adopted by dividing these different representations into Scenarios, Approaches and Models as shown in Table 2.

Table 2. Categorisation of life cycle scenarios, approaches and models

\begin{tabular}{|l|}
\hline Life Cycle Scenarios \\
\hline New product/facility/software design, development and introduction \\
\hline Transformational change \\
\hline Capability or service acquisition \\
\hline Life Cycle Approaches \\
\hline Base \\
\hline Experimental \\
\hline Incremental \\
\hline Evolutionary \\
\hline Life Cycle Models \\
\hline Management \\
\hline Development \\
\hline
\end{tabular}

The term Scenario is used to describe a context of the high-level strategies or plans to achieve specific goals. These scenarios will be shaped by factors that influence the business environment such as challenges, conditions, organisations and market requirements. Business Change Life Cycles as understood within Portfolio Management (Jenner \& Kilford 2011) are included within this category.

Approaches are representations of flows and interactions between discrete life cycle models (Adcock \& Farncombe 2009). Different approaches may be used for different scenarios and/or combine different models, and typically can be associated with programme delivery and transition planning.

Models are specific representations of a framework of processes and activities within each life cycle phase that depict the elements that are undertaken and how they relate to each other. A model comprises phases / stages, constituent processes, the products generated as outputs of those processes, and definitions of the roles and responsibilities in contributing to each process and the generation of each product.

PM practitioners need to understand these different representations when deciding upon the strategy that best addresses the portfolio, programme and/or project objectives. SE practitioners need to support PM practitioners in this by explaining the development needs, and the implications of the choice of life cycle on the overall project or programme strategy. An example of these categories and the relationship between them was included in the presentation given at ASEC 2015 by Gray \& Richardson (2015).

A combined conceptual life cycle model. To demonstrate how PM and SE interact (and the benefits of joined-up thinking), the JWG has extended a conceptual SE development model (Veemodel) to incorporate a management perspective based on an earlier PM representation (Chapman 
\& Gray 2014). Figure 3 shows the resulting combined Vee-model which highlights areas of overlap and where the two views complement or enhance each other ('touch points'). Future work in this area is intended to extend this representation (an extended Vee Model) to encompass the synergies between portfolio management and systems business modelling and analysis.

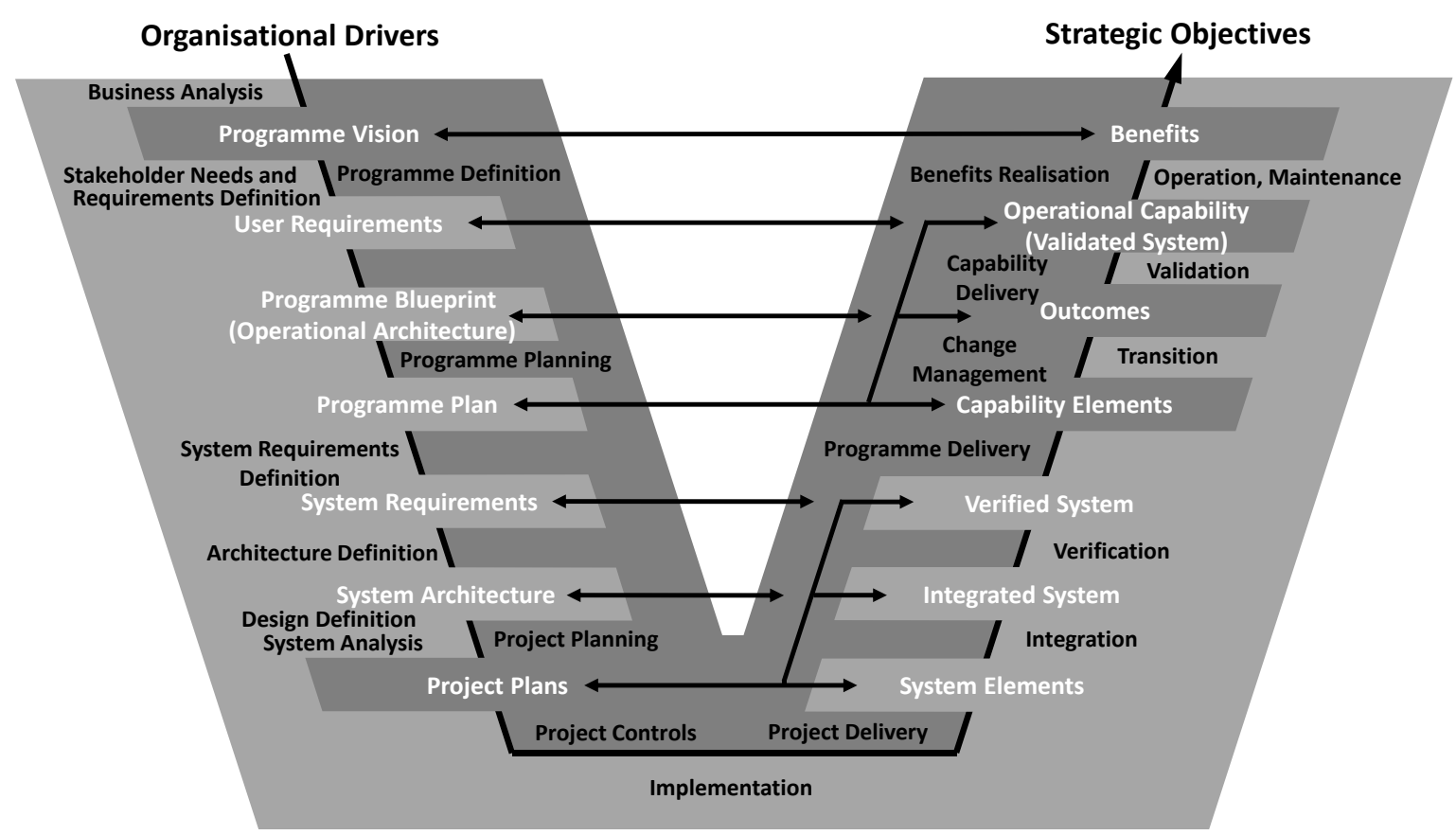

Figure 3: The SEPM Vee-model (the outer Vee represents SE processes, the inner Vee PM processes)

Touch points. The model identifies touch points where the two perspectives are looking to achieve the same objective but use different concepts or terminology. For example, both perspectives look to define current and future states but SE uses the concept of an Operational (or Enterprise) Architecture - the output of a modelling activity based upon an Architecture Framework - whereas PM uses the concept of a Programme Blueprint. Similarly, the two communities use different terms, Validated System (SE) and Operational Capability (PM) to describe the delivered system after transition to the operational environment ("Business as Usual").

Tensions. Tensions can arise not only from actual SE/PM perspective differences but also from preconceptions and mis-communications. Terminology clashes, over-elaboration in both requirement setting and project planning, overlaps or gaps in responsibilities and a failure to articulate the value of SE or PM processes to leaders or teams all contribute to tensions, underpinned by a lack of mutual understanding and respect (Fielding-Smith 2011).

In addition, any process issues are exacerbated by the 'tension fields' (see Figure 4) that operate within project environments due to the differing demands and objectives that are present. Both SE and PM practitioners must recognise and understand how their perspectives and actions both affect, and are affected by, these tensions.

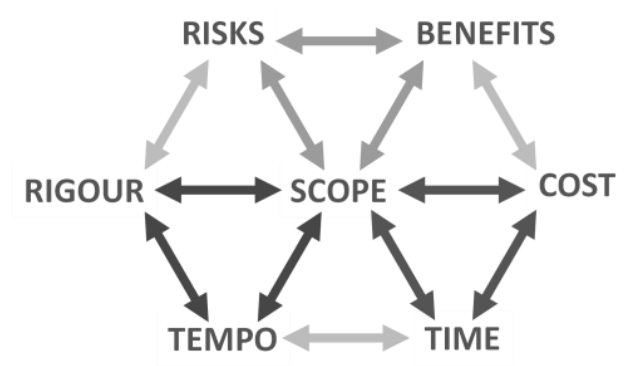

Figure 4: Project tension fields (with "Quality” being a universal field throughout) 


\section{SE / PM Fusion Points}

The review and analysis of processes within the SEPM Vee-model has also identified a number of examples that illustrate the benefits of greater SE and PM integration. Details of these fusions are currently under development and will soon be the subject of future SEPM JWG publications, but the following short descriptions encapsulate the direction of current developments that have arisen from the work described in this paper.

Employing SE techniques in project product-based planning. Product-Based Planning is a technique described in the PRINCE2® framework (Murray et al 2009) which becomes much more powerful when integrated with the Systems Engineering techniques used to develop the Product Breakdown Structure (PBS) and Work Breakdown Structure (WBS). This joint approach, which continues through the life cycle, provides a complete description of the work to be undertaken, the interdependencies and the acceptance criteria, which leads to robust planning and scheduling and hence a greater likelihood of project success.

Adopting a system of systems approach to programme definition and management. A systems of systems approach considers "a system-of-interest whose system elements are themselves systems; typically these entail large scale inter-disciplinary problems with multiple, heterogeneous, distributed systems" (SEHbk 2011), where the wider system has emergent properties over and above those of the individual sub-systems and where individual sub-systems that work together are interoperable, compatible and coherent. If a project can be considered as a system to deliver specific products, then a programme - "a group of related projects and change management activities that together achieve beneficial change for an organisation" (APMBoK 2012) - is focused on how these systems interact with each other, how to deliver an overall coherent capability, management of the external boundaries with business-as-usual operations, and dealing with stakeholders. There are therefore strong parallels with the challenges for developing a system of systems (e.g. potential independent operation, different life cycles, ambiguous initial requirements, fuzzy boundaries and complexity).

Utilising architectural modelling in defining programmes and projects. Enterprise architecture principles (or Model-Based Systems Engineering) are used in defining operational models for current and future states (Target Operating Models). These are also synonymous with the architectural principles behind programme blueprints as both disciplines are aimed at defining a holistic representation of all the elements that make up an operational state and what has to change.

Verification and validation in benefits management. Benefits realisation planning and delivery is focused on the definition of benefits, their dependencies and how (and when) these benefits are expected to be confirmed as realised. As such, benefits realisation planning demonstrates the means of verifying the benefit realisation in terms of the relationship with capabilities generated, outcomes achieved and transitions undertaken. Validation of the benefits comes with ensuring that the end benefits actually realised align with those that underpin the change vision (and detailed through the user requirements and blueprint). This activity can therefore be seen as a continuation of the integrated test, evaluation and acceptance planning and execution that form a key part of a systems engineering approach.

Identifying and managing project to project interdependencies. A key element of programme management, and a source of its potential complexity, is the recognition and management of interdependencies between projects (sub-systems), and between the projects and programmes and those elements outside the programme (system) boundary. These interdependencies represent information or physical items that pass across interfaces between different project or programme elements. In the SE environment, "focus is placed on controlling the interfaces between system elements and external systems" in order to help address ambiguity, fuzziness and complexity. Therefore a robust systems engineering environment, with its attendant focus and discipline around 
interfaces, should be fully integrated with the work of the project, programme or portfolio definition and execution.

Applying soft systems methods to stakeholder management. Two of the biggest challenges for Project or Programme Managers managing a complex 'soft' problem are the ability to properly understand and scope the problem, and the difficulties around managing a group of disparate stakeholders. Soft problems can often be emotive and so logic does not always prevail and stakeholders need to feel involved in the decision if the Programme is to have any hope of achieving milestones. Problems that involve human behaviour are particularly complex, and many projects fail because the 'human element' is not properly accounted for. Soft Systems Methodology (SSM) can be integrated with PM principles to effectively understand the complexity of a project, and the influence of the stakeholder environment on that complexity. SSM techniques can be used to achieve consensus, especially where there are differing opinions within the stakeholder community.

Using SE to improve the governance of complex projects. Project, programme and portfolio governance can be strengthened through incorporating key SE approaches, techniques and tools (and how these elements and processes interact), particularly in dealing with areas of higher complexity. Principles such as multidisciplinary approaches, integration, open modular design and integrated product teams can all support robust planning and controls leading to improved governance.

Requirements definitions in contract management. Strong contracts require a robust specification of the work to be undertaken (in particular outputs) and the relationships with other areas of the project. Specifications that are fully aligned with (and derive from) user and system requirements will therefore be integrated with the wider project. The test and acceptance criteria that will not only provide contractual confirmation for payment, but will also be aligned with project schedules and the vertical verification activity.

Transition definition and management. The purpose of the Transition Process in ISO15288:2015 is "to establish a capability to provide services specified by stakeholder requirements in the operational environment". It defines how to plan and perform the transition, and how to generate the requirements for a successful transition, installation procedures and constraints. It therefore fully supports the Realizing the Benefits process within the Managing Successful Programmes ${ }^{\circledR}$ framework (MSP®), which also describes the transition to business as usual operations for a change programme. By fusing the two disciplines a robust transition can be defined, particularly if the system of interest encompasses both the actual outputs/outcomes (i.e. the product system), the means of achieving these (the delivery system) as well as the immediate interfaces with the wider business and operational environment.

Managing change across the supply chain-based product delivery system. The whole-life holistic perspective of the SE disciplines, and their supporting processes, provides a firm platform for understanding how a change activity, and its subsequent introduction into normal steady-state operations, is to be achieved within the context of a supply chain. Links between the supply chain elements, and their relative importance at different stages of the life cycle, can be captured, modelled and implemented through systems engineering practices to arrive at a robust sustainable strategy for supply chain management for ongoing definition, production, implementation and through-life logistics support.

Integrating review gates throughout project delivery phases. The use of project level Review Gates as top-level milestones fuses SE and PM activities to the overall schedule at the start of the project and continues throughout the life cycle. The fusion between PM and SE activities that Gate Reviews provide helps realise benefits such as: improved fused project management and systems engineering at the start; improved visibility of project status, planning and risks, including countering cognitive biases; providing a forum for identification, capture and communication of 
lessons learned; increased understanding of the context of the project within the organisation, and maintaining improved PM and SE integration by requiring PM and SE staff to jointly present progress to date and gain buy-in for the plan to the next gate.

\section{Results from selected Case Studies}

The following sections describe key elements arising from the various case studies. These have been grouped together under headings that relate to the following Principles and Top Tips that have been derived by the JWG on the basis of the findings from the Group's various activities.

\section{Integrated Programme - Thameslink}

A 'One team' approach. In the Thameslink Programme an integrated team was set up from the beginning in recognition of the UK Department of Transport and the Professional Services Contractor (PSC) approach of combining Systems Engineering and Integration (SE\&I) with Programme Management and Controls (PM\&C). This created the platform for design and programme integration on Thameslink to flourish, thereby playing a key role in the enhancement of time, cost and quality performance.

An integrated plan. The Thameslink Programme implemented an integrated SE/PM approach that focussed on an Integrated Plan with the creation of a tool called the 'Roadmap'. The aim was to provide clarity to the programme and ensure the programme was prepared to cope with enhanced capacity, performance and operations, as well as highlighting and facilitating the management of top-level risks, assumptions and issues.

The SE/PM teams worked successfully together using the Roadmap Tool to define the composition of the programme and the sequence of deliverables through a series of system architectures. These helped identify the critical operational issues requiring change, and the need for an infrastructure operations and control strategy to be developed.

Integrated governance. The Systems Integration (SI) Team reported to the Systems Integration Authority (SIA). The SIA's key responsibilities were to provide direction to the work of the Systems Integrator - including setting decision-making boundaries, identifying strategic issues which the Systems Integrator team needed to address, and providing oversight of programme-level change control against a configuration-controlled baseline programme.

\section{East London Line Programme}

Common and clear communication. The creation of an 'Engineering Strategy' provided a structural approach to stakeholder engagement and approval process during the East London Line Programme, bringing the Engineering and Project Management teams together. It was a critical process that drove stakeholder communication on the programme and decision making for key aspects of the design.

The main examples of engagement include effective communication through presentations, the production of an Engineering Management Plan (supported by a System Assurance Plan), an Intranet-based Process Management System (based on the Project and Engineering Lifecycles), and System-Level Stage Gate Reviews. The production of a well-structured, logical document hierarchy was implemented to ensure consistency of definitions for technical terminology used on the programme.

Collaborative environment. The PM team were proactive in removing the barriers to good SE processes and the use of SE tools supported the PM team in their tasks, including support for collaborative working with all of the contractors. SE was central to the project and was not a separate team; this encouraged collaborative working amongst engineers and project managers. The 
team worked with the mind-set of 'engineering in a systematic way' ${ }^{6}$. This avoided the perception that the application of SE was something apart, and helped to focus the entire team on using a requirements-driven approach.

A 'One team' approach. A systems integration approach was adopted from the start, ensuring that assurance was progressively checked at every stage of the design and construction of the project. The project was managed by a Transport for London (TfL) led Integrated Project Team (IPT) which included the Programme Management Team and an Engineering Team.

\section{UK National Air Traffic Service - Prestwick Air Traffic Control Centre}

Benefits of SEPM. The SEPM teams worked together to identify, elicit and capture all requirements from all stakeholders within sufficient timescales. The early capture of requirements allowed for the effective planning of the project including implementing processes to progressively approve various elements of the works and to provide a fully integrated solution.

Recognition of tensions. SE and PM staff worked in collaboration to develop a staff communications plan with details of the staff migration from the existing Manchester control centre to the new centre in Prestwick. Whilst the use of traditional SE \& PM techniques was employed in the detail behind the plan, perhaps the most important aspect was involved with the organisational change of the control centre with the migration of the project team since these staff were central to the viability of the new centre.

A 'One team' approach. During the initial design phase of the project, the SE and PM teams worked in unison through the application of PM and SE techniques. Developing an integrated team provided an environment for innovation and enabled any problems arising from change to be solved as they became apparent.

\section{Heathrow Terminal 5 (T5)}

Defining a collaborative environment. This major project provided an example of how all processes and principles of SE and PM were required to be brought together so the project could work as one system and ultimately operate to British Airport Authority (BAA) requirements. The'T5 Agreement' - a legal document which assumed that the client would bear the risk on T5 encouraged collaborative behaviour and was designed to improve BAA and partners' working in integrated project teams. The T5 Agreement was a channel to collaboration between a large number of leading contractors (38-40 contractors working under the T5 agreement) which put safety as the highest priority of the project followed by programme and cost.

BAA prepared, developed and refined a novel approach that was used to deliver the project. A standardized process called 'Continuous Improvement Project Process' (CIPP) was based on a set of replicable processes such as standardized designs and modular components, integrated project teams involving BAA, and framework agreements to work on a long-term basis with first-tier suppliers.

\section{Results from the identification of the Principles}

The Principles. These Principles serve as generic good practice for projects and can be applied to interfaces between all disciplines and not just PM and SE practitioners. They are the result of looking at the main reasons for project failure and the analysis of the root causes.

\footnotetext{
${ }^{6}$ Quotation taken from interview with East London Line personnel. Refer to Nasser (2016).
} 
The Principles are:

1. Common Goal. The need for both disciplines to be striving towards solving the same solution and ensuring they are addressing the right problem.

2. Scope. Defining the scope from the outset of a project can prevent confusion and tension. It is also why it is so difficult to recover projects when a systems engineer is parachuted in late.

3. Clarity of Responsibility. Ensuring all members of the team are clear on their responsibilities and their timelines for delivery when defining the scope.

4. Common Clear Communication. This principle refers to both internal and external communication. At times, System Engineers and Project Managers can communicate with external stakeholders in ways that can seem diametrically opposed.

5. Mutual Respect and Recognition. Good working relationships start with understanding the value that the other discipline brings to the project.

6. Recognise and Manage Tensions. Healthy tension between Systems Engineering and Project Management disciplines can drive a great outcome for a project. These tensions need to be recognised and managed to drive performance.

7. Establish Collaborative Behaviours. Planning upfront is important. All projects will face emergent issues, however, and resolving these in a collaborative manner across disciplines will ensure the optimum solution.

The key barriers. During the workshops and the interviews there were some definite themes concerning the barriers to effective integration of the two disciplines. The main barriers identified were documentation, the use of language, the perceived value of the disciplines, the understanding of risk, planning and estimating, organisational silo mentality and decision making.

\section{Tips for successful integration between SE and PM}

Based on the principles and the barriers, Table 3 presents the JWG's Top Tips for Successful SEPM Integration.

Table 3: Top Tips for Successful SEPM Integration

\begin{tabular}{|l|l|}
$\begin{array}{l}\text { Promote the value of } \\
\text { integration and systems } \\
\text { thinking }\end{array}$ & $\begin{array}{l}\text { Be clear on the benefits of each discipline } \\
\text { Clearly articulate the benefits of integration } \\
\text { Continue to develop discipline competency } \\
\text { Establish a community to run internal induction and training sessions }\end{array}$ \\
\hline $\begin{array}{l}\text { Create a collaborative } \\
\text { environment of healthy } \\
\text { challenge }\end{array}$ & $\begin{array}{l}\text { Clarify language } \\
\text { Clarify roles, responsibilities and behaviours }\end{array}$ \\
\hline & Recognise tensions at the outset and manage throughout the project \\
\hline Develop an integrated plan & $\begin{array}{l}\text { Agree the sequence of deliverables } \\
\text { Tailor the design of the delivery system as well as the product }\end{array}$ \\
\hline $\begin{array}{l}\text { Integrate early and manage } \\
\text { through the project life cycle }\end{array}$ & Establish integrated governance (programme \& technical) \\
\hline
\end{tabular}




\section{Conclusions}

The value of integrated working and different perspectives. SE and PM are both ways of thinking about complex problems, ways of delivering enduring change, and ways of combining disparate disciplines. Even within the limited areas of life cycle representations and processes there are significant synergies, overlaps and tensions between the two perspectives, and these all offer opportunities for SE and PM practitioners to recognise and appreciate each other's perspective and contributions in order to collaborate for mutual benefit.

SE underpins the solution planning-development-delivery project lifecycle by providing the necessary discipline to the specification, design, implementation, testing and delivery of project outputs. PM helps to establish the 'business context' within which the SE activities are undertaken, and to understand the wider system of interest and its external influences. Addressing complexity, providing appropriate rigour, understanding the true system of interest, removing unproductive tensions and improving the recognition of risks will all result in tangible benefits to the organisation.

After reviewing and analysing several different case studies it is clear that common goals and similar activities exist within Project Management and Systems Engineering. When these are combined and work collaboratively, efficiencies and advantages can be realised on projects. Evidently there is not a 'one size fits all' method to project management and systems engineering working jointly together. Each project needs to be assessed on an individual basis in order to gain the greatest value, but if the time is taken to do this at the outset of the project then efficiencies will be achieved in terms of schedule, cost and quality.

The set of principles and top tips (based on the case studies as well as the wider Body of Knowledge generated by the JWG) will help to support the work of the wider SE and PM communities in undertaking this increased early joint working, and obtain the benefits of SE and PM integration.

The work of the SEPM JWG embraces many other aspects of SE/PM integration beyond the opportunities identified in the assessment of life cycles and processes, case studies and principles for improved understanding. Further information and guidance material will be published in due course to provide practitioners with the awareness, understanding, tools and techniques to deliver greater value from the benefits of integrated working.

An enduring 'one team' approach. As a result of the work of the JWG and directly arising from a recommendation by the JWG, the Association for Project Management established an enduring Specific Interest Group (SIG) on Systems Thinking in December 2016. Run jointly with INCOSE $\mathrm{UK}$, this incorporates the role of the JWG and should ensure that a long-term relationship is maintained. This Systems Thinking SIG sits alongside fourteen other similar SIGs within the APM on disciplines such as Planning Monitoring and Conrol, PMOs, People, Contracts and Procurement, Governance, Risk Management and Benefits Management, thus integrating further the concepts of Systems Thinking and Systems Engineering into the Project, Programme and Portfolio Management Body of Knowledge. Information on the Systems Thinking SIG can be found at http://www.apm.org.uk/community/systems-thinking-sig.

\section{Acknowledgements}

The authors would like to acknowledge the help and support of all the members of the Joint Working Group in the generation of the material summarised in this paper. We would also like to thank Duncan Kemp and Adrian Pyne for general advice and inputs, and Dr James Goodwin for the genesis of the categorisation of life cycles. We would also like to acknowledge the time and inputs of those interviewed in support of the case studies. 


\section{References}

Adcock R, Farncombe A., 2009. “Are our life-cycle approaches up to current and future needs?”, INCOSE UK Autumn Assembly 2009 [available through http://incoseonline.org.uk/Program_Files/Calendar/Show_Event_Details.aspx?CatID=Events\&EventID $=107:$ accessed 5th May 2015]

APMBoK 2012. Association for Project Management Body of Knowledge, 6th edition, Princes Risborough: APM [available through https://www.apm.org.uk/body-of-knowledge ]

Brain \& Gibson 2011. "The rise and fall of the systems engineering lifecycle", INCOSE UK Bristol Local Group 2011 [available at http://incoseonline.org.uk/Program_Files/Calendar/Show_Event_Details.aspx?CatID=Events\&EventID $=198:$ accessed 4th May 2015]

Chapman J, Gray A, 2014. "Joining the dots: An introduction to programme management", “APM Presents...' Conference 2014, London [available at https://www.apm.org.uk/news/apm-presentsjoining-the-dots ; accessed 29th May 2015]

Cooke A, Rooke K. 2015. "Good to great: Major projects need the right blend of project management and systems engineering skills", APM Conference 2014, London [https://www.apm.org.uk/apm-conference/archive-2015/\#Andy]

Cowper D, McGlynn J. 2013. "Project Management \& Systems Engineering Joint Working Group", INCOSE UK ASEC 2013 Workshop

[http://incoseuk.org.uk/Documents/Groups/Engineering_and_Project_Management/PM_SE_ASEC201 3_Final_10_Nov_2104.pdf: accessed 17th June 2016]

Gray A. Richardson K. 2015. "Valuing our place in the world: Using Systems Engineering in Programme and Project Management", INCOSE UK ASEC 2015

[http://incoseonline.org.uk/Documents/Events/ASEC2015/Papers/Valuing_our_place_in_the_world.pdf accessed 17th June 2016]

Fielding-Smith 2011. "Integrating programme management and systems engineering: A mutualistic approach", INCOSE UK ASEC 2011 [available through

http://incoseonline.org.uk/Program_Files/Calendar/Show_Event_Details.aspx?CatID=Events\&EventID =178: accessed 4th May 2015]

Murray A, Bennett N, Edmonds J, Patterson B, Taylor S, Williams G. 2009. Managing successful projects with PRINCE2®, London:TSO

Nasser H. 2016, "WS5 Case Studies Executive Summary”, APM/INCOSE UK Joint Working Group (Currently in preparation: available Spring 2017 via http://www.apm.org.uk/community/systems-thinking-sig ).

Rooke K. 2015 'Getting things done right and getting the right things done: Results from ASEC 2015 Workshop', APM/INCOSE UK Joint Working Group

ISO15288:2015, ISO/IEC/IEEE 15288:2015, Systems and software engineering — System life cycle processes

ISO21500:2012, BS ISO 21500:2012, Guidance on project management, First edition 2012-09-01

Jenner S, Kilford C. 2011, Management of Portfolios, 2011 Edition, London:TSO

SEHbk 2011. Systems Engineering Handbook: A Guide for System Life Cycle Processes and Activities, version 3.2.2, Revised by M. Krueger, D. Walden, and R. D. Hamelin. San Diego, CA (US): INCOSE

SEPM JWG 2013, Aims and Objectives [text available at http://incoseonline.org.uk/Groups/Project_Management_and_SE/Main.aspx?CatID=Groups\&SubCat= Project_Management_and_SE, accessed 29th May 2015]

SEPM JWG 2014, SEPM Joint Working Group Outputs, INCOSE UK, ASEC 2014 [available at http://incoseonline.org.uk/Documents/Groups/Engineering_and_Project_Management/ASEC2014_SE PM_JointWorkingGroupPoster_2_v3.pdf: accessed 5th May 2015] 


\section{Biographies}

Andrew Gray is an experienced project and programme manager with practical and theoretical knowledge of the management of engineering activities across the product development cycle. With a background in the aerospace sector he has led teams in multi-discipline and multi-cultural environments. He now works for BMT Hi-Q Sigma where he advises clients in all aspects of complex change management. A European and UK Chartered Engineer and a member of INCOSE, APM and the RAeS (and a founder member of the JWG), he is the secretary of the Systems Thinking SIG and a co-author of the APM's "Introduction to Programme Management".

Dr Adrian James is currently the Director of teaching at UCL Australia, a department of University College London, where he teaches PM in the MSC in Energy Resources Management. He has over 15 years practical experience in the technical PM and SE fields, mainly in the space sector. In the UCL Centre for Systems Engineering he taught on the MSc in Systems Engineering Management and on the APM Practitioner course. Since 2004 he has developed and delivered professional development courses in SE and PM. He is a fellow of the APM, and a member of the AIPM, SESA and INCOSE, (previously holding positions on the UK IAB and UK Board).

Helen Nasser is a civil engineer by training and holds a Master in Programme and Project Management and an MBA. With 7 years' experience working on major infrastructure Projects in Venezuela, France and the UK in the construction and rail industry, Helen is a founder member of the JWG and lead the workstream for the case studies that had successfully applied SE and PM. Helen joined the Rail Business of WSP in May 2013 and contributes to delivery of major Rail Projects for the UK and she strongly believes that a joint application of SE and PM is instrumental for project success.

Ken Richardson leads the Consultancy Practice Area at Roke, a leading UK technology and consulting company. He has successfully led multidisciplinary teams on many bids and projects across the defence, national security and commercial domains throughout his career. In recent times he has combined this with strategic leadership across the areas of Systems Engineering, Defence Capability Research and Decision Support. Since 2013 he has represented INCOSE UK as a member of the JWG and copresented the paper "Valuing our place in the world - Using Systems Engineering in Programme and Project Management" at INCOSE UK's Annual Systems Engineering Conference in November 2015.

Kate Rooke is a highly competent Systems Engineer who combines proven technical skills with a strong leadership ability to effectively deliver organisational objectives. An original member of the SEPM Joint Working Group, she served as an Air Engineer in the Royal Navy for 10 years and then joined PA Consulting where she leads the delivery of complex change programmes in defence. She has a wealth of experience in both project management and systems engineering and firmly believes that a good relationship between the disciplines is critical for success.
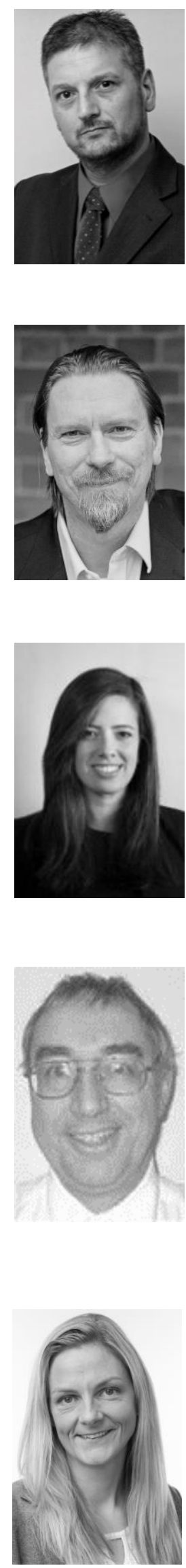